\title{
Obesity and Metabolic Syndrome Overview
}

\author{
WAYNE GADE, JEAN GADE
}

INDEX TERMS: Obesity, metabolic syndrome, cardiovascular disease, diabetes.

\section{Clin Lab Sci 2010;23(1);37}

Wayne Gade, PhD, MT(ASCP), Associate Professor, Clinical Lab Science Program, University of Illinois Springfield, Springfield, IL

Jean Gade, MS, BS(RN), Nurse Educator, Lincoln Prairie Behavioral Health, Springfield, IL.

Address for Correspondence: Wayne Gade, Clinical Laboratory Science \& Chemistry Departments, HSB Rm 314, One University Place, Springfield, IL 62703, wgade1@uis.edu, 217-725-6384.

Wayne Gade, PhD, MT(ASCP) is the Focus: Obesity and Metabolic Syndrome guest editor.

Modern societies suffer from an obesity epidemic, despite considerable societal pressure to be thin. The epidemic persists in spite of the widely accepted notion

The Focus section seeks to publish relevant and timely continuing education for clinical laboratory practitioners. Section editors, topics, and authors are selected in advance to cover current areas of interest in each discipline. Readers can obtain continuing education credit (CE) through P.A.C.E. by completing the continuing education registration form, recording answers to the examination, and mailing a photocopy of it with the appropriate fee to the address designated on the form. Suggestions for future Focus topics and authors, and manuscripts appropriate for $C E$ credit are encouraged. Direct all inquiries to the Clin Lab Sci Editorial Office, Westminster Publishers, 315 Westminster Court, Brandon MS 39047. (601) 214-5028, (202) 315-5843 (fax).westminsterpublishers@comcast.net. that obesity is unhealthy, unattractive, and shortens life expectancy. Conservation of energy (the first law of thermodynamics) tells us that obesity must result when caloric intake chronically exceeds caloric expenditures. Historically, physiologic control mechanisms suppressed appetite and promoted physical activity, enabling most people to avoid a positive energy balance. But what forces compel modern humans, the most intelligent and rational of beings, to chronically exceed their caloric requirements?

In the first article, we compare the development of obesity to a "highway" whose destination is obesity. This "Highway to Obesity" has many "entrance ramps" that represent the many biological, genetic, and psychological factors that underlie overindulgence. We explore the genetic deficiencies and biological tendencies that predispose one toward obesity. In recent decades, these inherited tendencies toward obesity are more likely to be expressed, due to easy access to high calorie foods and decreased physical activity. Complete genetic deficiencies rarely occur and generally result in early-onset, morbid obesity. More commonly, obesity involves a gradually acquired dysregulation of hormonal systems that initially limit obesity. However, when these fragile feedback mechanisms become overwhelmed and fail, hormone resistance actually favors weight gain.

Article one also examines the multitude of comorbidities associated with obesity. These include type II diabetes, atherosclerosis, hypertension, congestive heart failure, pulmonary disease, several forms of cancer; renal disease, liver and gall bladder diseases, polycystic ovarian syndrome, coagulation disorders, sleep apnea, stroke, osteoarthritis, gynecological problems, and ocular diseases. But just how does obesity affect physiological changes that promote such a wide array of diseases? 
The second article explores metabolic syndrome (MSX), an array of symptoms that are known to increase the risk of cardiovascular disease. These include insulin resistance, hyperglycemia, elevated lipid levels, and increased abdominal fat deposition, all factors known to compromise metabolic and cardiovascular health. The article describes numerous biochemical changes that damage cellular function, collectively termed lipotoxicity, which often translates into organ failure when obesity becomes extreme.

The next article in this series, which appears in a subsequent issue, will illustrate the clinical lab results (lipid panels, hormone levels, etc.) expected from several obese patients whose weight gain has resulted from different physiological or psychological conditions. A fourth and final article describes how a previously healthy individual's lifestyle choices have contributed to the development of obesity and metabolic syndrome. In this case, we follow the progression from an athletic teenager with normal metabolic and endocrine function to an obese middle aged patient who has developed leptin and insulin resistances, glucose intolerance, abdominal obesity, hyperlipidemia, hypertension, and atherosclerosis. school enrolling approximately 23,000 students. The University is located in Southeastern Michigan an educationally rich and culturally sophisticated region including historic Ypsilanti, neighboring Ann Arbor and the Detroit metropolitan area. The College of Health and Human Services includes four schools: Health Sciences, Health Promotion and Human Performance; Nursing and Social Work with over 80 tenure track faculty serving more than 2,500 undergraduate and 580 graduate students. The College offers 117 undergraduate and 13 graduate degree programs (http://www.emich.edu/chhs). The College stands out from its peers in many ways priding itself on exceptional teaching, emphasizing both fundamental and applied research. All of our academic programs provide a collaborative, hands on community based learning environment. The College of Health and Human Services is located primarily in the Marshall Building- a recent construction with a "green design".

All applications must be made online at https://www.emujobs.com - Posting \#FA1006E. Applications must include a cover letter, curriculum vitae, statement of research and teaching interest and contact information for three references. The position will remain open until filled but preference will be given to applicants submitting all requested documents by Jan 15, 2010. For questions about this position contact the search chair, Lynne Shetron-Rama, PhD, MT (ASCP) at lshetron@emich.edu or (734) 487-2381. EOE 